\title{
Analysis of Water Droplet Evaporation through a Theoretical-Numerical Model
}

\author{
Giulio Lorenzini ${ }^{1}$ and Onorio Saro ${ }^{2^{*}}$ \\ ${ }^{1}$ University of Parma, Department of Industrial Engineering, Parco Area delle Scienze 181/A, Parma \\ 43124, Italy \\ ${ }^{2}$ University of Udine, Politechnic Department of Engineering and Architecture, via delle Scienze 208, \\ Udine 33100, Italy
}

Email: onorio.saro@uniud.it

\begin{abstract}
An analytical model previously defined and numerically transposed via a Runge-Kutta 4-th order method is here employed to thoroughly describe a water droplet travelling in air from a sprinkler nozzle down to the ground. The study, aimed at a realistic description of the process, is completed by a number of analysis parameters which contribute to fully describe the system, the phenomenon and the mutual affections that characterise the study in relation to the droplet travel distance, the droplet time of flight, and the final droplet temperature. The few assumptions superimposed do not alter the reliable picture arrived at. The results, provided in the form of figures and comments, enable the reader to well understand the phenomenon and to realise which parameters prove more effective on conditioning the whole process. A general applicability of such results to define rational irrigation policies appears extremely evident and is supported by the treating provided.
\end{abstract}

Keywords: Analytical model, Numerical method, Water droplet evaporation, Water droplet travel distance, Water droplet time of flight, Final droplet temperature, Parameters effect.

\section{FOREWORD}

The focus of this paper is that of analysing, within the process of a flying water droplet evaporating in air, how each influential parameter acts in relation to the principal research variables, such as droplet travel distance, droplet time of flight, and final droplet temperature.

The process is imagined in the frame of sprinkler irrigation practice, while the water droplet is intended as a sphere leaving the nozzle, following its aerial path and finally touching the ground; such sphere is subject to evaporation all the way down its path and consequently changes its mass and volume without solution of continuity.

To well understand the whole phenomenon and to be able at describing it in an objective way, it is essential to explore how the dynamic and thermal-fluiddynamic parameters vary while the process is in evolution. To do so, the following variables are to be assessed and computed meanwhile the process evolves: droplet diameter, air temperature, droplet initial velocity, diffusion coefficient of water in air, wind velocity, air relative humidity, initial droplet temperature, solar irradiance, initial droplet throw inclination.

The variables just quoted will be thoroughly analysed in this paper, to arrive at the comprehension of the full picture of the phenomenon taken into consideration.

A number of publications have been considered to better frame the topic treated in the present research within the international scientific literature scenery: they will be now summarised as part of the study carried out.

In [1], treating droplet evaporation in the perspective of fire safety, a mathematical model of unsteady evaporation for a spherical and semitransparent to radiation water droplet was developed, adopting a radiative transfer model to calculate the local volumetric rate of radiation absorption. Moreover, the effects of thermal expansion and temperature-dependent thermophysical properties on the evaporation process were considered, together with the internal circulation in the droplet. This approach was not shared in the present paper as Bi [-] was always 1.t. 0.1 in the simulations made for this research. The results showed that the absorption of radiation by the droplet significantly affects its lifetime and proved that neglecting it causes an underestimation of water evaporation and an overestimation of the droplet lifetime for droplets with not too small diameters.

In [2] water droplets evaporation was described as an unsteady process undergoing many possible heat and mass transfer conditions. The modelling was performed via a combined analytical-numerical research of heat and mass transfer in a two-phase flow, determining how the heating manner affects the droplet state change without neglecting the radiant absorption in water droplets. Such influence on the droplet surface temperature modifies the gradient of the 
droplet temperature. Moreover, vapour flow, spreading from the droplet surface, resists an inflow of hot gas towards the droplet, so increasing the dimension of the thermal boundary layer and decreasing the intensity of convective heating towards the droplet, if compared to convective heating of a solid sphere.

Also interesting is the approach provided in [3], where it was modelled the change of thermal state and phase transformation intensity of sprayed water (and other liquids) droplets heated by conduction; in their study the influence of the Knudsen layer was neglected and warming and evaporation of the droplets did not affect the state of the air flow where the droplets stay. Among their results, it was shown that it existed a particular change of the thermal state of the sprayed liquid expressed by the Fourier number. Such change can be described as change of a droplet surface, centre, and mean mass temperatures, significantly affected by the temperature of the gas mixture and by the partial pressure of the liquid vapour in it. As a whole, the numerical study performed allowed for an easy evaluation of the unsteady heat and mass transfer parameters of the sprayed liquid systems and a complete assessment of the transfer process interaction in a two-phase droplet and gas flows.

Deepening the investigation, in [4] it was employed a combined theoretical and numerical approach to compute the variation of the thermal state of a sprayed liquid droplet. The heat and mass transfer occurring are treated as unsteady, as well as the hydrodynamic and radiant interactions occurring to the droplets. Neglecting the Knudsen layer's influence, the authors determined the characteristic curves representing the change of transfer parameters, in case of droplets heated by conduction. Such curves linked the thermal state change parameters variation to the phase transformation for droplets with identical initial liquid temperature. The effect of more complicated boundary conditions on the interaction of the transfer processes were also considered.

Still of the same research team is paper [5], where it was modelled the heat transfer interaction in large water droplets during an unsteady phase transformations process, with special care to heating and augmentation of condensing water droplets and according to the iterative method of numerical research. The study covered a combined assessment of energy transfer in a semitransparent droplet and of droplet heating and evaporation, computing the droplet surface temperature from an energy fluxes balance to and from the surface. Furthermore, it was determined that the thermal state of an evaporating droplet relies on the particular heating performed and the assessment of the heat stored in exhaust flue gas employed by water injection was also considered.

Also useful, for the general information provided is paper [6], where the author derived a model, whose equations are then solved numerically, to describe the evaporation in quiescent air of a single spherical droplet affected by different environmental parameters. Results showed that the droplet evaporation rate drops for increasing air temperature, keeping relative humidity as constant. For further increased ambient temperatures condensation was shown to occur which leads to an increasing droplet diameter. Moreover, an attempt of facing a liquid spray was also made via an evaporation model implemented in a CFD code, to show the affection of spray evaporation on the gaseous phase, whose temperature drops due to the energy required by the phase change.

Interesting considerations may also be evicted by an examination of [7], which faces the problem of a droplet of pure water, inserted in a climatic chamber and kept suspended in air by a suitable electromagnetic field, evaporating in a nitrogen environment in function of temperature. The time scale of the process matched with that of droplet growth in clouds. The water droplet dynamics, also in relation to its evaporation, was analysed by means of a laser light scattering method, taking into account the kinetic effects near the droplet surface and avoiding errors introduced by instrumental humidity measurement.

Still focusing on water droplet evaporation is the work in [8], which studied experimentally and theoretically the influence of the thermal effects of the substrate on the behaviour of a pinned sessile water droplet evaporating into air in a hydrophilic and hydrophobic condition. The results proved that, increasing the substrate temperature, the role of the thermal-linked mechanisms becomes increasingly important; moreover, it was proved how the contact angle evolves as the temperature increases and the crucial role played by the nature of the substrate in the evaporation of a sessile droplet. In general, the global evaporation rate proved to be significantly affected by the thermal effusivity of the substrate.

Recently, an experimental investigation [9] focusing on the effect of initial sizes and velocities of water droplets on integral characteristics of its transfer (motion trajectories, velocities, sizes, relative concentration) was performed through in a high temperature (more than $1000 \mathrm{~K}$ ) environment. Two optical methods ("Particle Image Velocimetry" and "Interferometric Particle Imaging") were employed in the analysis of two-phase gas-vapor-droplet mixtures. The study identified different possible kinds of droplet motion through the gas flow, in intensive evaporation conditions, assessing the possible affections that help predict such motions.

Even if the general droplet shape hypothesis was different from that adopted in the present study, useful considerations could also be evicted by the experimental investigation [10], where it was studied the general behaviour of "big and slow" water droplets, having diameters from 3 to $6 \mathrm{~mm}$ and velocities from 0.5 to $5 \mathrm{~m} \mathrm{~s}^{-1}$, changing their shapes when dropping within a gaseous mean. Temperature, both of the mean and of water, was also a parameter and varied from 275 to $1100 \mathrm{~K}$ and from 275 to $360 \mathrm{~K}$, respectively. In particular, optical techniques were employed to assess the displacement velocity of droplets and the liquid convection as a function of time, monitoring the shape changes via a high-speed camera, so providing the mutual dependence of droplet shapes, velocities and sizes. Moreover, the shape-variation parameters, such as amplitude, length and period, were assessed in function of the gaseous mean and droplets, revealing how the droplets geometric and dynamic parameters are bound to their shape and period of oscillation.

Concluding the first section of this paper, it should be reminded that the present research was performed employing the formulation of the analytical model recently defined and validated in [11]; this same model was then numerically implemented, via a Runge-Kutta 4-th order method, by means of Visual Basic for Applications (VBA) programming language.

\section{PROBLEM ANALYSIS}

The basis of the whole research performed for the present paper is the theoretical-numerical model for a sprinkler water 
droplet in flight, reported in [11]: that study took advantage of the simplified analytical model in [12]; the latter mainly accounted for the dynamic effects of the process, thus being a partial contribution to the full solution of the problem, while the former considered all the analysis variables and the mutual non-linear interactions between one another, thus being an ultimate description of the actual problem of an evaporating sprinkler water droplet.

In the present paper, to avoid any redundancies, we will not report those models in detail but just the general conditions and hypotheses that supported the equations set, together with the variable ranges under examination, so to well frame the approach followed.

The hypotheses adopted are the following:

- the physical system considered is a single droplet exiting from the nozzle of a sprinkler and generated exactly in correspondence to the nozzle outlet;

- the forces applied to the system are weight, buoyancy and friction;

- $\quad$ the droplet has a spherical shape all the way down;

- friction has the same direction of velocity for all the path but opposite sense;

- the volume of the droplet is variable throughout the flight due to its continuous evaporation;

- wind is a vectorial entity affecting the droplet flight in every possible direction/sense;

- $\quad$ air humidity is a parameter study;

- $\quad$ radiation is a parameter study;

- diffusion of air in water is negligible;

- the sprinkler nozzle is at height $\mathrm{z}=0 \mathrm{~m}$;

- the droplet path is that associated to the trajectory range (i.e. when the vertical co-ordinate turns back to 0 );

- $\quad$ virtual mass action and Basset force are negligible;

- $\quad$ the water droplet is isothermal (Bi always 1.t. 0.1)

- the flow state can be Stokes law, intermediate law, or Newton law, depending on Re [-] [13];

- $\quad$ film $\operatorname{Pr}[-]$ kept equal to 0.7307 ;

- $\quad$ film Sc [-] kept equal to 0.6016

From these hypotheses it can be evicted that the study here performed is for sure physically realistic as no significant simplification has been introduced in the description of the phenomenon.

To complete the model setting it is now necessary to define the variables ranges:

1. $\mathbf{V}_{\mathrm{i}:}: 5 \mathrm{~m} \mathrm{~s}^{-1}, 15 \mathrm{~m} \mathrm{~s}^{-1}, 25 \mathrm{~m} \mathrm{~s}^{-1}, 30 \mathrm{~m} \mathrm{~s}^{-1}$;

2. $\delta: 10^{\circ}, 25^{\circ}, 40^{\circ}, 55^{\circ}, 70^{\circ}$;

3. $\mathrm{D}_{\mathrm{i}}: 0.1 \mathrm{~mm}, 0.4 \mathrm{~mm}, 0.7 \mathrm{~mm}, 1 \mathrm{~mm}, 2 \mathrm{~mm}, 3 \mathrm{~mm}, 4$ $\mathrm{mm}, 5 \mathrm{~mm}, 6 \mathrm{~mm}$;

4. G: $0 \mathrm{~m} \mathrm{~s}^{-1}, 1 \mathrm{~m} \mathrm{~s}^{-1}, 2 \mathrm{~m} \mathrm{~s}^{-1}, 3 \mathrm{~m} \mathrm{~s}^{-1}, 4 \mathrm{~m} \mathrm{~s}^{-1}$ in three directions and two senses;

5. $\mathrm{T}_{\mathrm{a}}: 300 \mathrm{~K}, 305 \mathrm{~K}, 310 \mathrm{~K}, 315 \mathrm{~K}, 320 \mathrm{~K}$;

6. $\mathrm{T}_{\mathrm{w}}: 288 \mathrm{~K}, 296 \mathrm{~K}, 304 \mathrm{~K}, 312 \mathrm{~K}, 320 \mathrm{~K}$;

7. $\varphi: 0 \%, 10 \%, 20 \%, 50 \%, 70 \%$;

8. $\mathrm{D}_{\mathrm{v}-\mathrm{a}}: 0.200 \mathrm{~cm}^{2} \mathrm{~s}^{-1}, 0.225 \mathrm{~cm}^{2} \mathrm{~s}^{-1}, 0.250 \mathrm{~cm}^{2} \mathrm{~s}^{-1}$, $0.275 \mathrm{~cm}^{2} \mathrm{~s}^{-1}, 0.300 \mathrm{~cm}^{2} \mathrm{~s}^{-1}$;

9. $\mathrm{I}_{\mathrm{sol}}: 0 \mathrm{~W} \mathrm{~m} \mathrm{~W}^{-2}, 250 \mathrm{~W} \mathrm{~m}^{-2}, 500 \mathrm{~W} \mathrm{~m}^{-2}, 750 \mathrm{~W} \mathrm{~m}^{-2}$, $1000 \mathrm{~W} \mathrm{~m}^{-2}$.

Moreover, the forces acting on the droplet during its aerial path are:

- gravity;

- buoyancy;

- friction.
The numerical implementation considered that the problem faced is a Cauchy one (known the initial conditions and the differential equations ruling the process) and applied a Runge-Kutta fourth order method, implementing the model via a Visual Basic for Applications (VBA) programme [14].

\section{OUTCOMES}

To better comprehend the complex process which is being assessed, it is now essential to deepen the force-due and heatdue effects on the mutually affecting variables defining the study carried out.

The droplet travel distance $\mathrm{L}[\mathrm{m}]$ is the first topic we will be focusing on, being extremely important for the full understanding of the phenomena acting on a flying water droplet.

As it is obvious, determining the locus where irrigation shows its effects is extremely important from a practical point of view because it helps the operators in deciding the suitable policies in view of the choice for the best practices, also depending on the ambient parameters. In addition, setting the dependencies between $\mathrm{L}[\mathrm{m}]$ and the research variables helps to indirectly check the analytical model's performance.

Figures from 1 to 9 will display the effect of the different variables under examination on the droplet travel distance. In particular: Figure 1 is about the $\mathrm{L}[\mathrm{m}]-\mathrm{D}_{\mathrm{i}}[\mathrm{mm}]$ relation. The general trend is not far from a linear one but highlights that larger droplets tend to augment their travel distance less than smaller droplets, as gravity and friction (related to shape and especially velocity) increase their effect with $\mathrm{D}_{\mathrm{i}}[\mathrm{mm}]$.

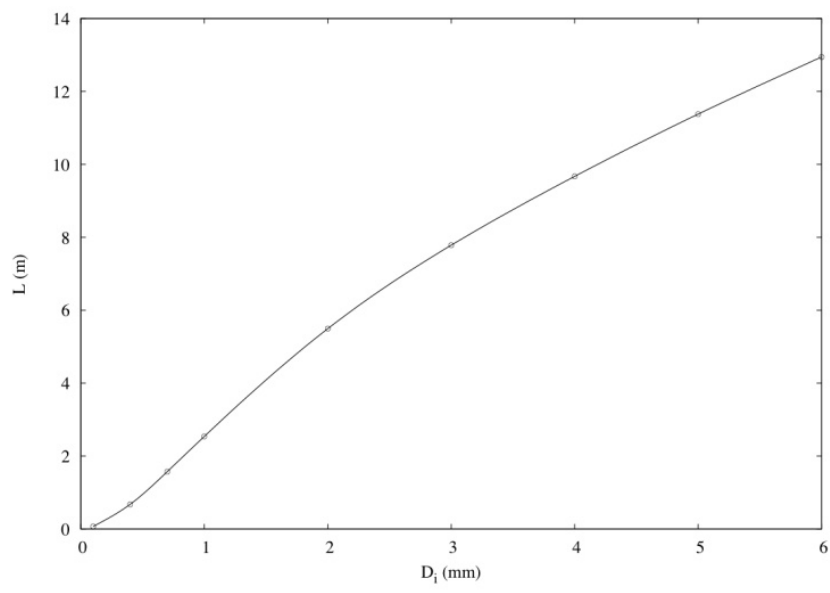

Figure 1. $L$ versus $D_{1}$

A less intense but not negligible effect is shown in Figure 2 that of the air temperature $\mathrm{T}_{\mathrm{a}}[\mathrm{K}]$. In fact, proving the sound predictive ability of the theoretical-numerical model adopted, as the environmental temperature raises, more water evaporates during the in-air droplet path, thus causing a weight and size reduction which allows a longer distance to be covered by the droplet itself. Thus, the small percentage raise of droplet mass evaporated with $\mathrm{T}_{\mathrm{a}}[\mathrm{K}]$ [11], is here associated to a consequent $\mathrm{L}[\mathrm{m}]$ increase. 


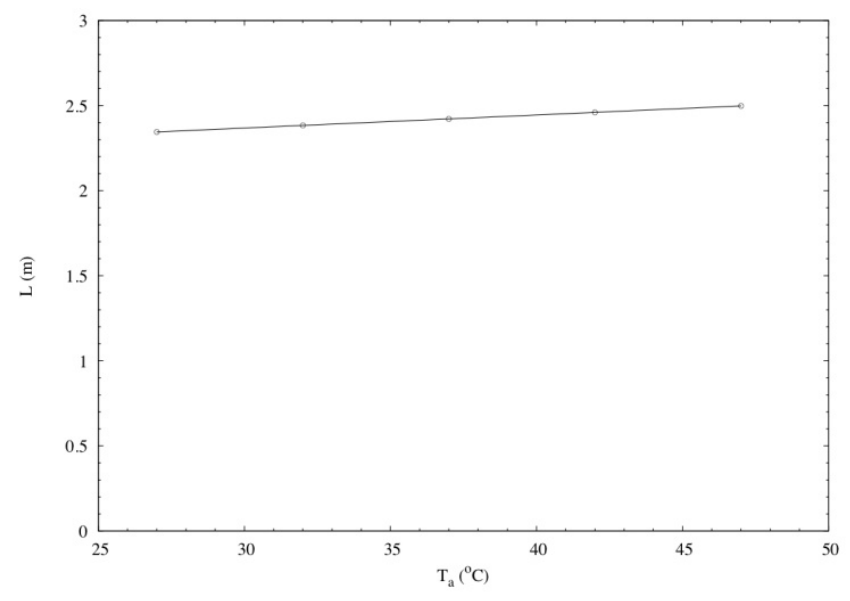

Figure 2. $\mathrm{L}$ versus $\mathrm{T}_{\mathrm{a}}$

An extremely interesting and remarkable effect on the travel distance is that of $\mathrm{V}_{\mathrm{i}}\left[\mathrm{m} \mathrm{s}^{-1}\right]$, initial droplet velocity. As showcased in Figure 3, as far as the droplet initial velocity keeps under its mean-range value, a quite steep slope characterises the effect of $\mathrm{V}_{\mathrm{i}}\left[\mathrm{m} \mathrm{s}^{-1}\right]$ on $\mathrm{L}[\mathrm{m}]$. The trend becomes successively flatter highlighting that, for higher initial velocities, the air friction effect tends to become more dominant thus limiting, with a power 2 strength, the potential droplet path.

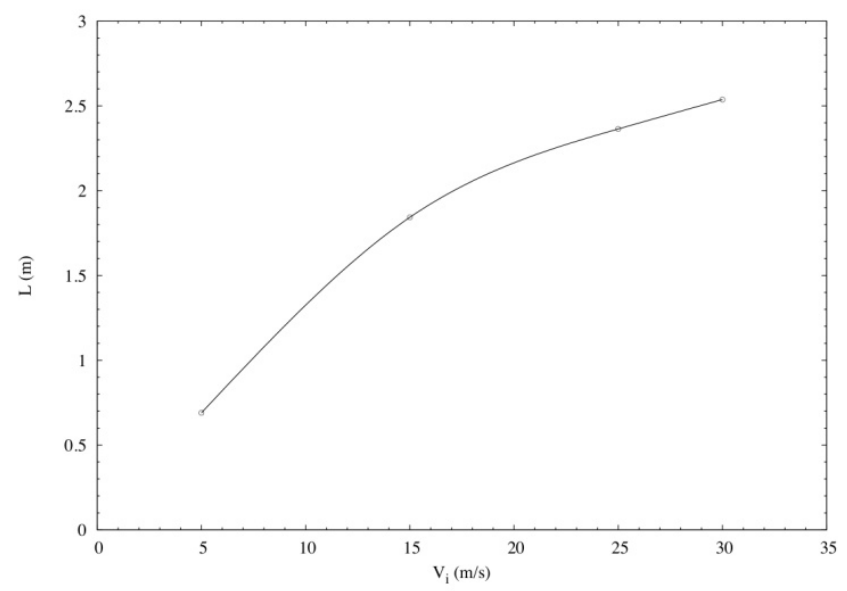

Figure 3. $L$ versus $V_{i}$

Less significant, within the range analysed, is the effect of $\mathrm{D}_{\mathrm{v}-\mathrm{a}}\left[\mathrm{cm}^{2} \mathrm{~s}^{-1}\right]$, diffusion coefficient of water in air, on $\mathrm{L}[\mathrm{m}]$. This can be clearly evicted by the almost flat curve in Figure 4 , regardless a $50 \%$ increase of the independent variable. What requires a closer examination is now the wind velocity (i.e. vectorial) effect on $\mathrm{L}[\mathrm{m}]$. The model, in fact, took into account the whole variable as a vector called $\mathrm{G}\left[\mathrm{m} \mathrm{s}^{-1}\right]$. Such approach, not documented in the literature, is original as it considers wind velocity not just as an unwanted or random variable but as a well defined affecting parameter, thus perfectly describable and manageable within a technical approach. As it may be observed in Figure 5, where the $\mathrm{x}$ and $\mathrm{y}$ wind velocity components (same direction and normal direction to $\mathrm{V}_{\mathrm{i}}\left[\mathrm{m} \mathrm{s}^{-1}\right]$, respectively) are taken into consideration as synergistic to $\mathrm{V}_{\mathrm{i}}\left[\mathrm{m} \mathrm{s}^{-1}\right]$, the travel distance, always computed as modulus, is broadly affected by $\mathrm{G}\left[\mathrm{m} \mathrm{s}^{-1}\right]$ and it may even invert the droplet's way or somehow deviate its direction.

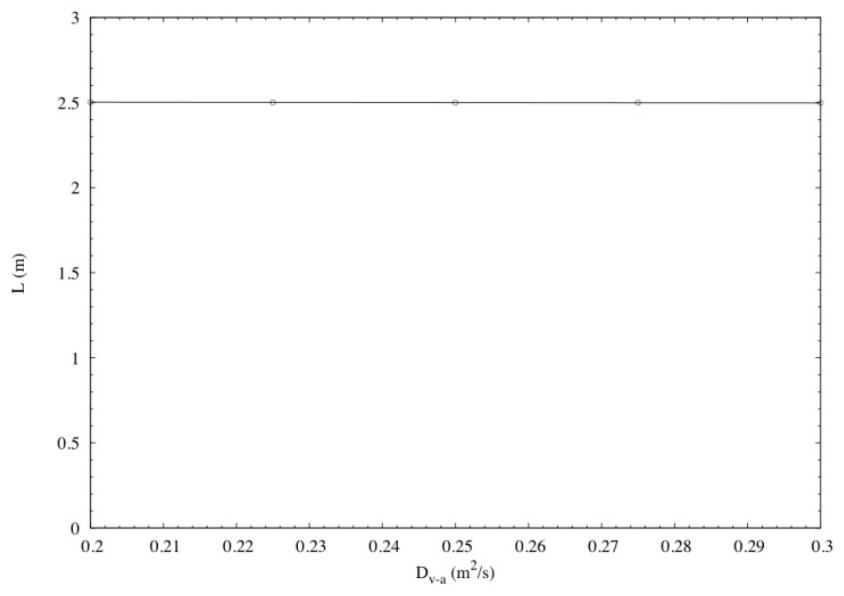

Figure 4. $L$ versus $D_{v-a}$

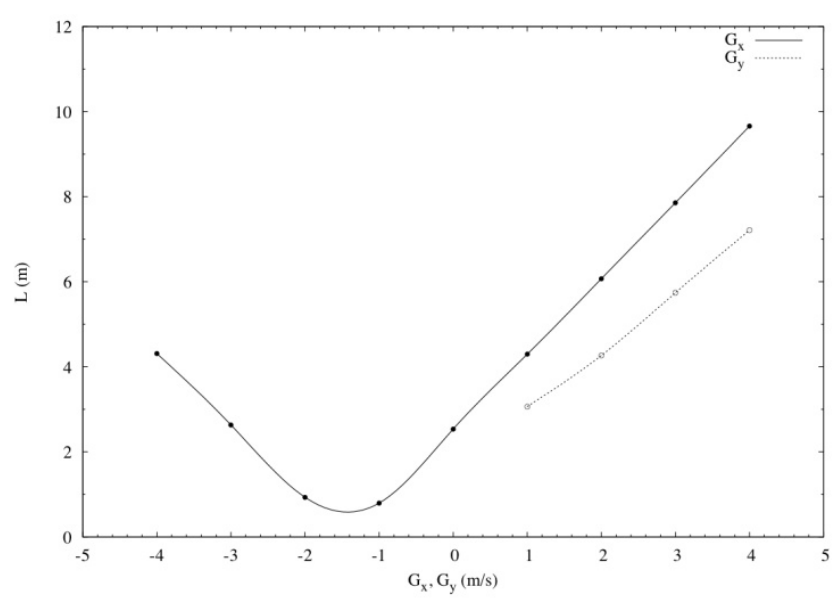

Figure 5. $L$ versus $G_{x}$ and $G_{y}$

Further insight may be attained checking Figures 6, 7 and 8 Figure 6 shows in detail how the $\mathrm{G}_{\mathrm{x}}\left[\mathrm{m} \mathrm{s}^{-1}\right]$ values tested and acting oppositely to $\mathrm{V}_{\mathrm{i}}\left[\mathrm{m} \mathrm{s}^{-1}\right]$ may affect the aerial droplet's path, squeezing it $\left(G_{x}=-1 \mathrm{~m} \mathrm{~s}^{-1}\right)$ or even inverting its original way.

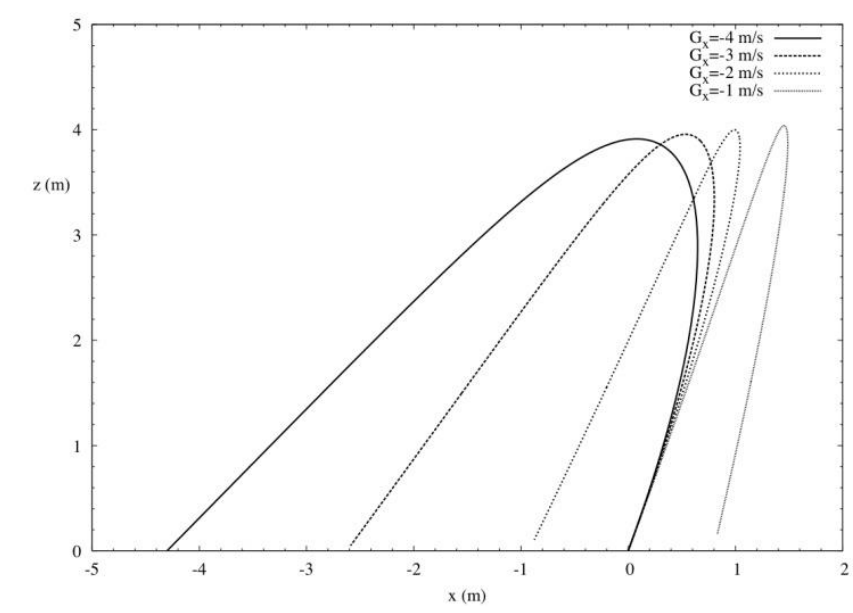

Figure 6. droplet path in the horizontal and vertical directions

The realistic predictions of the model are dynamically evident when observing Figures 7 and 8, which suitably showcase different combinations of the wind velocity components. The sensitivity of the model becomes evident in 
the droplet path modifications due to the velocity combinations superimposed in concurrent directions.

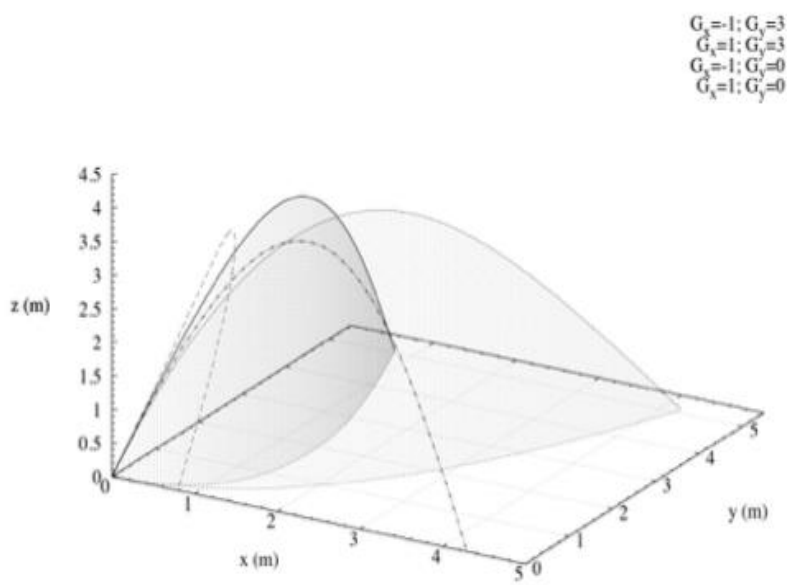

Figure 7. 3D droplet paths for different wind velocities

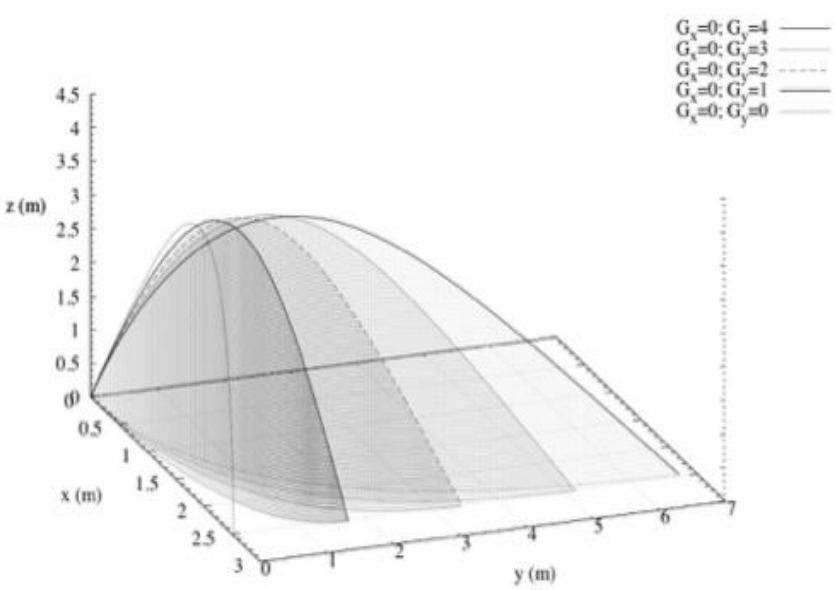

Figure 8. 3D droplet paths for different wind velocities

Another parametric dependence to be investigated is that of air relative humidity $\varphi[\%]$ on the droplet travel distance $\mathrm{L}$

[m]. Figure 9 graphs such relation within the range examined, i.e. $0 \div 70 \%$. Again, what is extremely important for its thermal-fluiddynamic effect (i.e. the droplet's phase change)

[11], prove to be not so effective dynamically speaking: in

fact a significant raise of $\varphi[\%]$ is associated just to an extremely limited augmentation of $\mathrm{L}[\mathrm{m}]$.

An even smaller parametric effect on the droplet travel distance is that of $\mathrm{T}_{\mathrm{w}}[\mathrm{K}]$, initial droplet temperature and $\mathrm{I}_{\mathrm{sol}}$ $\left[\mathrm{W} \mathrm{m}^{-2}\right]$, solar irradiance, within the range of values tested.

The latter also was not particularly effective on droplet evaporation, the former instead was able at doubling it [11]:

both here present a flat profile, see Figures 10 and 11.

A more varied trend is that linking $\mathrm{L}[\mathrm{m}]$ to $\delta\left[{ }^{\circ}\right]$, initial droplet throw inclination. Figure 12 shows that the travel distance soars passing from $10^{\circ}$ to $25^{\circ}$, successively dropping for wider angles.

As displayed, it is useful to compare such trend to the corresponding trend of the time of flight, which on the contrary augments monotonically with a slightly logarithmic relation: the travel distance decreases even if the time of flight increases, due to the upwards path covered by the droplet; in practice this is due to the definition of travel distance.

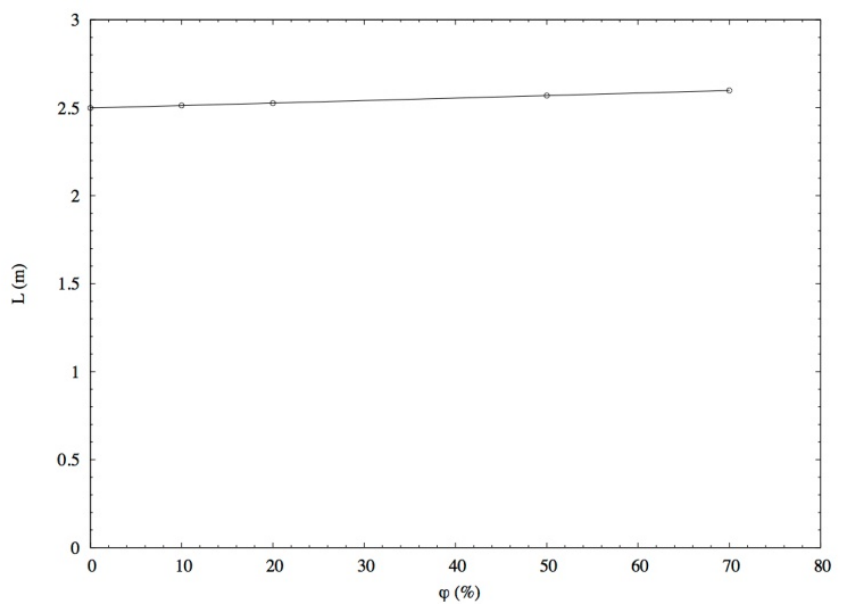

Figure 9. L versus $\varphi$

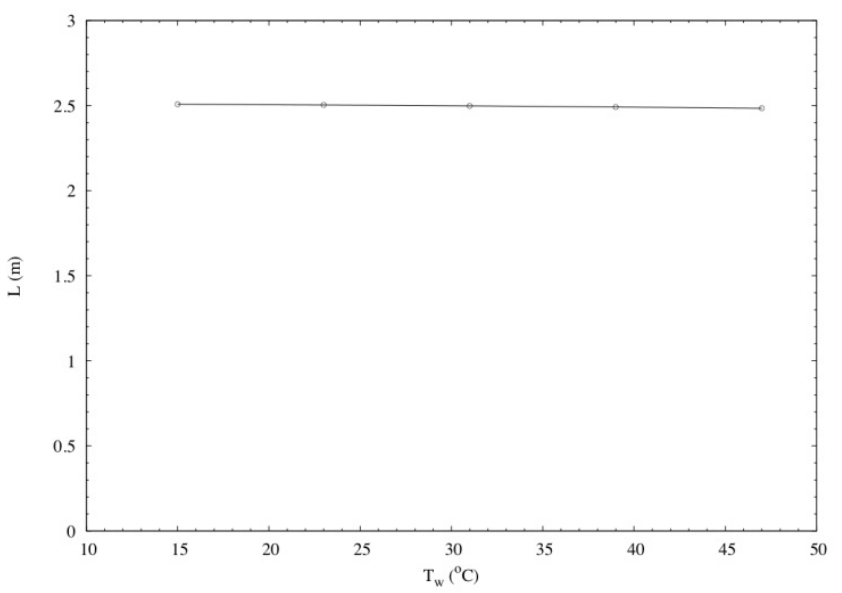

Figure 10. $L$ versus $T_{w}$

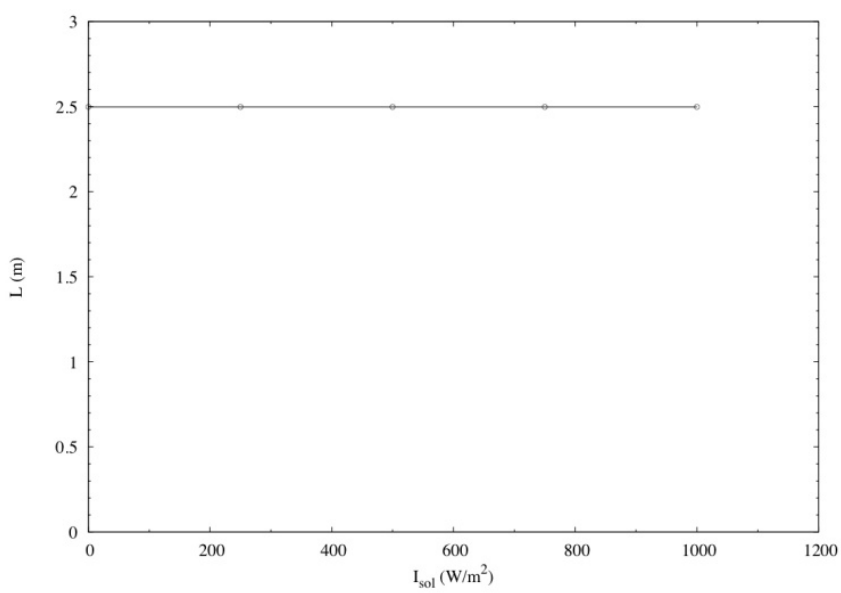

Figure 11. $L$ versus $I_{\text {sol }}$

Another relevant dynamical parameter to be examined more in depth is for sure the droplet time of flight $\tau$ [s]. This was partly analysed in [11] as part of the model validation, but needs here further consideration to widen the picture. Again, the whole set of analysis parameters is to be evaluated to check the effect of each of them on $\tau$ [s].

Figure 13 displays the droplet initial diameter - time of flight relation. It is worth noting that, if for bigger diameters a linear increase of $\tau[\mathrm{s}]$ is attained, for smaller ones (i.e. for $\mathrm{D}_{\mathrm{i}}$ [mm] 1.t. $1 \mathrm{~mm}$ ) a steeper slope highlights the strong effect of droplet evaporation for smaller droplets and the synergistic 
action of air friction on the flying sphere [11].

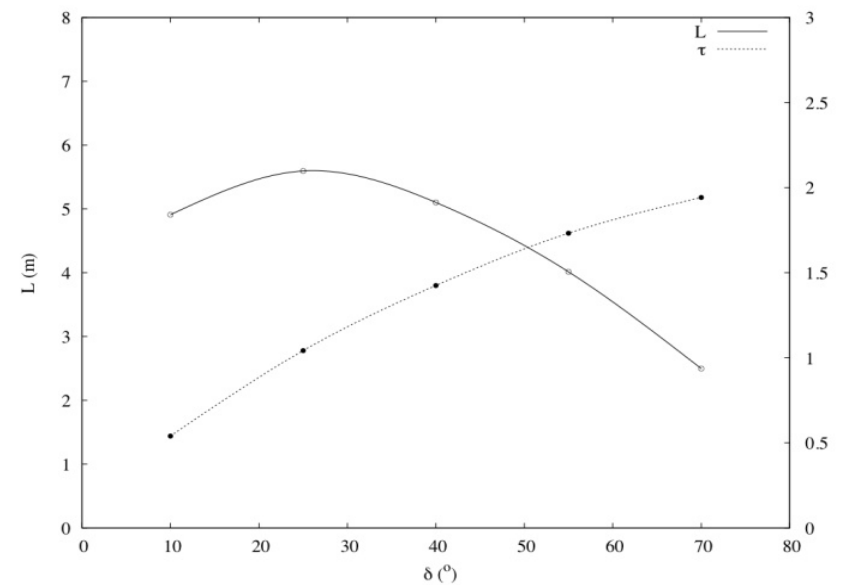

Figure 12. $L$ versus $\delta$; $\tau$ versus $\delta$

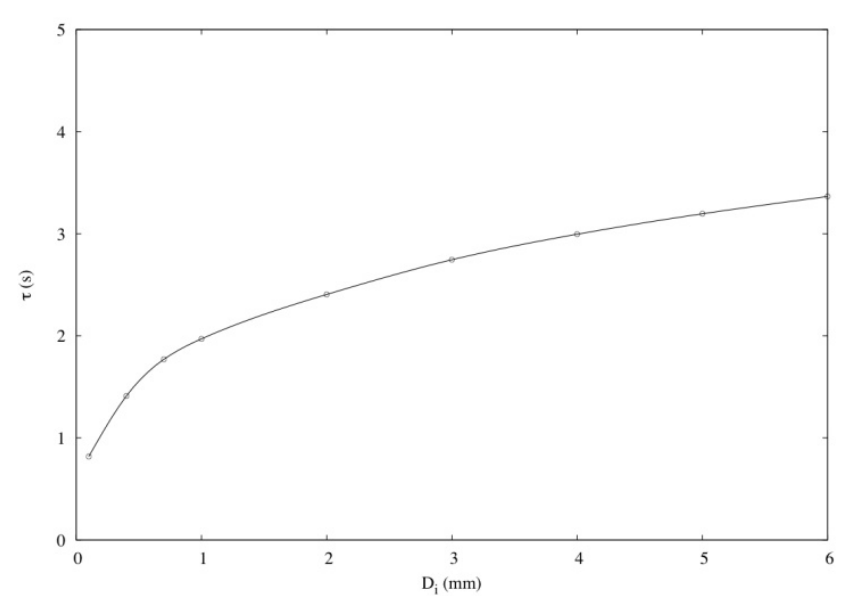

Figure 13. $\tau$ versus $D_{i}$

An apparently less interesting result is that available in Figure 14: a quite flat trend graphs the dependence of $\tau$ [s] on the air temperature $\mathrm{T}_{\mathrm{a}}[\mathrm{K}]$, thus pointing out a weak mutual relation. This is, on the contrary, a very interesting result as it confirms indirectly that, due to the restrained effect of $\mathrm{T}_{\mathrm{a}}[\mathrm{K}]$ on $\mathrm{M}_{\mathrm{ev}}$ [\%] (droplet mass evaporated in flight, see paper 11) in the range tested, an extensive variation of the time of flight is also unlikely.

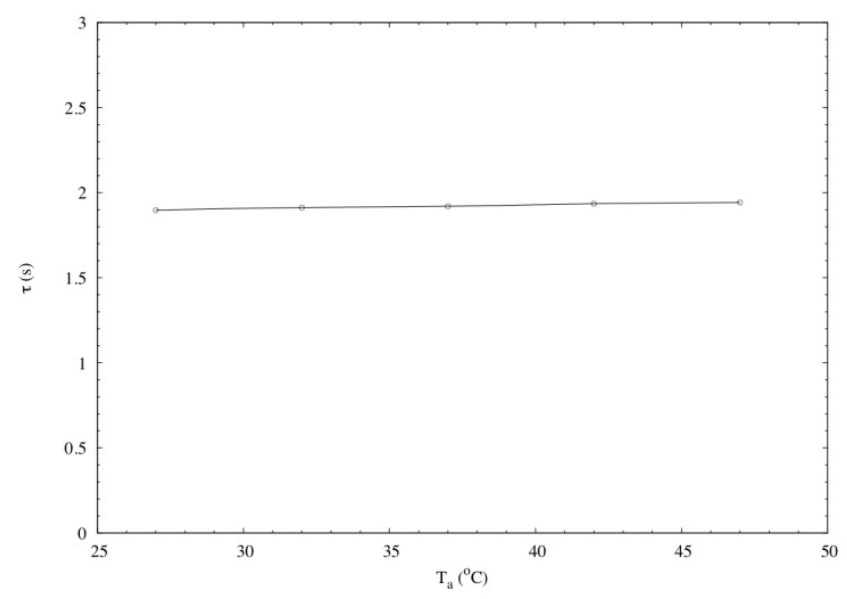

Figure 14. $\tau$ versus $T_{a}$
A similar trend may be spotted in Figures 15, 16, 17, 18 and 19 for what pertains the effect on $\tau$ [s] of the following variables, respectively: $D_{\mathrm{v}-\mathrm{a}}\left[\mathrm{cm}^{2} \mathrm{~s}^{-1}\right], \mathrm{G}_{\mathrm{x}}\left[\mathrm{m} \mathrm{s}^{-1}\right]$ and $\mathrm{G}_{\mathrm{y}}[\mathrm{m} \mathrm{s}$ $\left.{ }^{1}\right], \mathrm{I}_{\mathrm{sol}}\left[\mathrm{W} \mathrm{m}^{-2}\right], \mathrm{T}_{\mathrm{w}}[\mathrm{K}], \varphi[\%]$. But, if the comments on the trends in Figures 15, 16 and 17 could have been at all similar to those performed when analysing Figure 14 thus deserving no repetition, a few more words are to be spent on the other two just quoted.

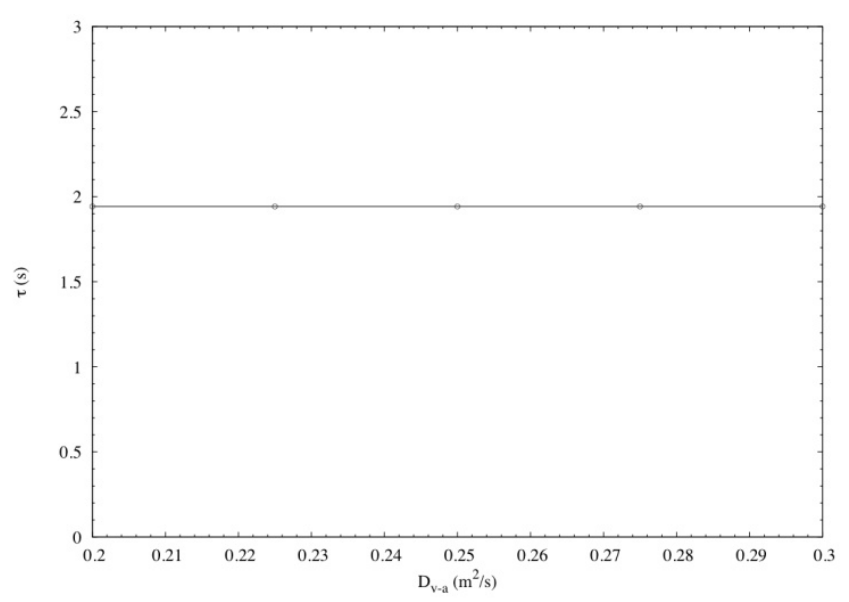

Figure 15. $\tau$ versus $D_{v-a}$

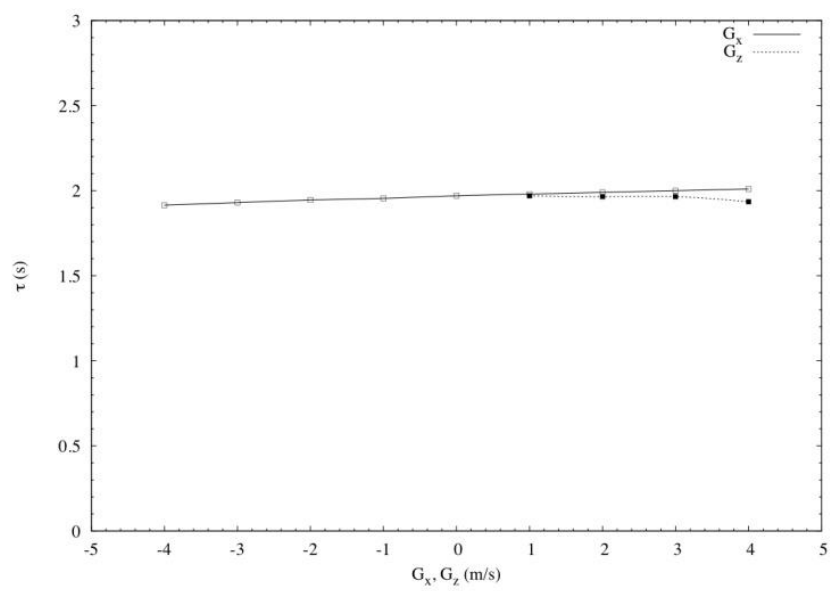

Figure 16. $\tau$ versus $G$

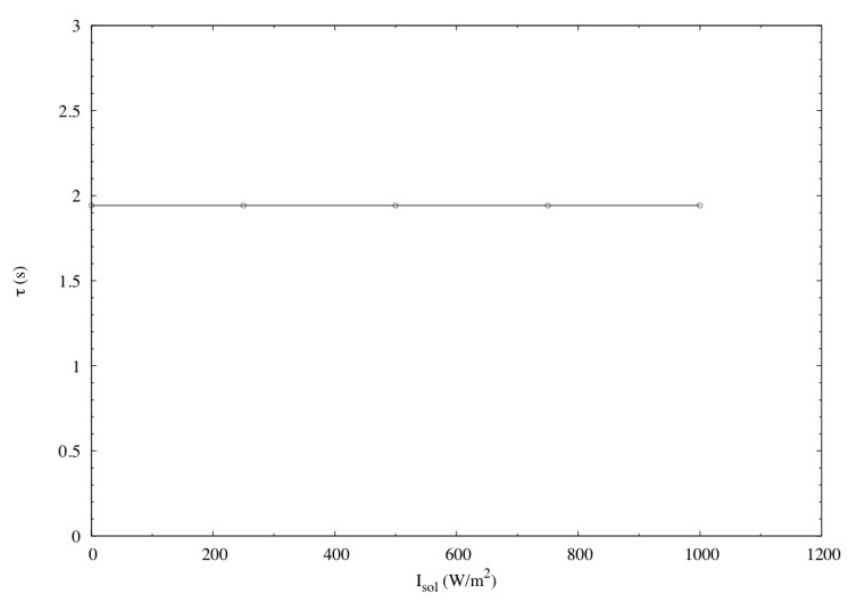

Figure 17. $\tau$ versus $I_{\text {sol }}$

In detail: in Figure 18, showcasing the interaction between $\mathrm{T}_{\mathrm{w}}[\mathrm{K}]$ and $\tau[\mathrm{s}]$, the time of flight keeps almost unchanged, 
as a whole, regardless to a more intense evaporation $\left(\mathrm{M}_{\mathrm{ev}}[\%]\right.$, paper 11), because such phenomenon is partly compensated by a less intense air friction (due to the droplet shrinking) and by a reduced weight.

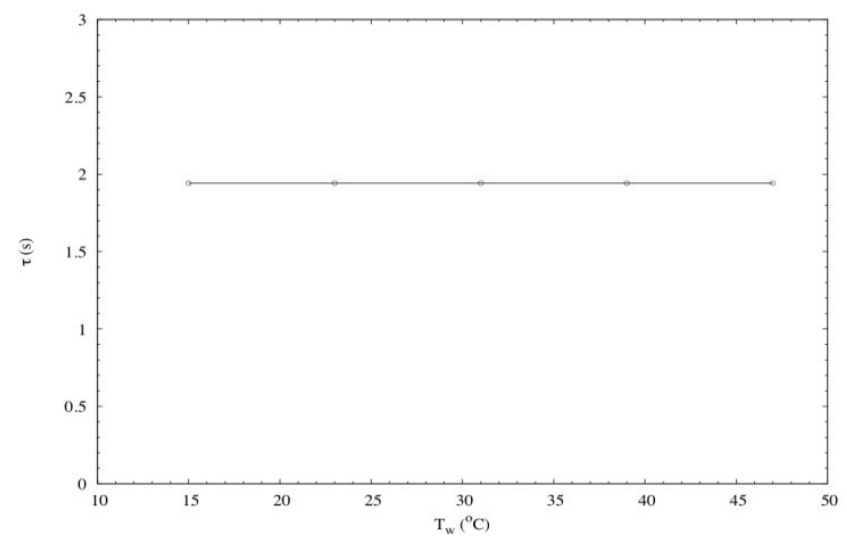

Figure 18. $\tau-\mathrm{T}_{\mathrm{w}}$

In Figure 19, instead, the apparent absence of a correlation between $\varphi[\%]$ and $\tau[\mathrm{s}]$ is due to the array of reference values chosen to standardise the present investigation and in particular to the value of $D_{i}[\mathrm{~mm}]$ here adopted.

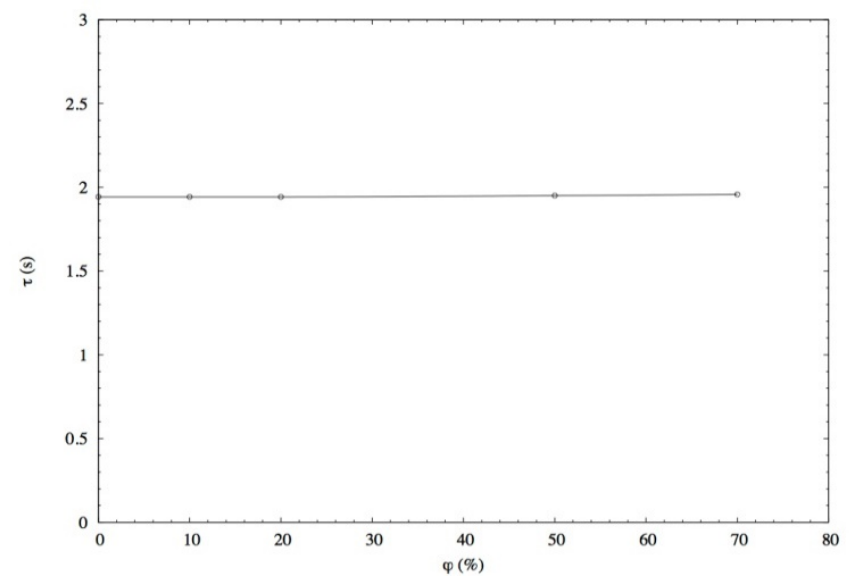

Figure 19. $\tau$ versus $\varphi$

As for the dependence of $\mathrm{M}_{\mathrm{ev}}[\%]$ on $\mathrm{V}_{\mathrm{i}}\left[\mathrm{m} \mathrm{s}^{-1}\right]$ (see paper 11 ), also that of $\tau[\mathrm{s}]$ on $\mathrm{V}_{\mathrm{i}}\left[\mathrm{m} \mathrm{s}^{-1}\right]$ showcases (Figure 20) a direct proportionality which is linked to the general laws of ballistics.

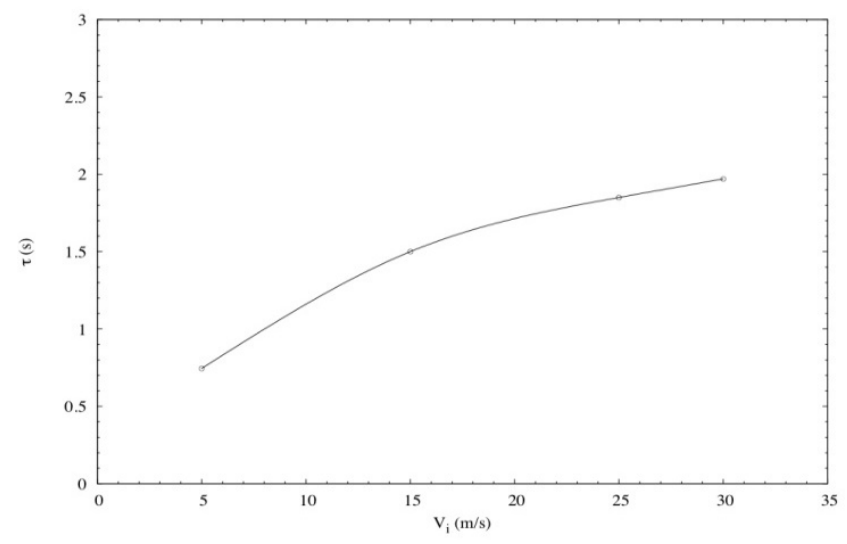

Figure 20. $\tau$ versus $V_{i}$
Figure 21 is also extremely interesting as it reflects the full reliability of the analysis performed: due to the effect of air friction the time of flight assumes its higher values for bigger values of $\delta\left[{ }^{\circ}\right]$.

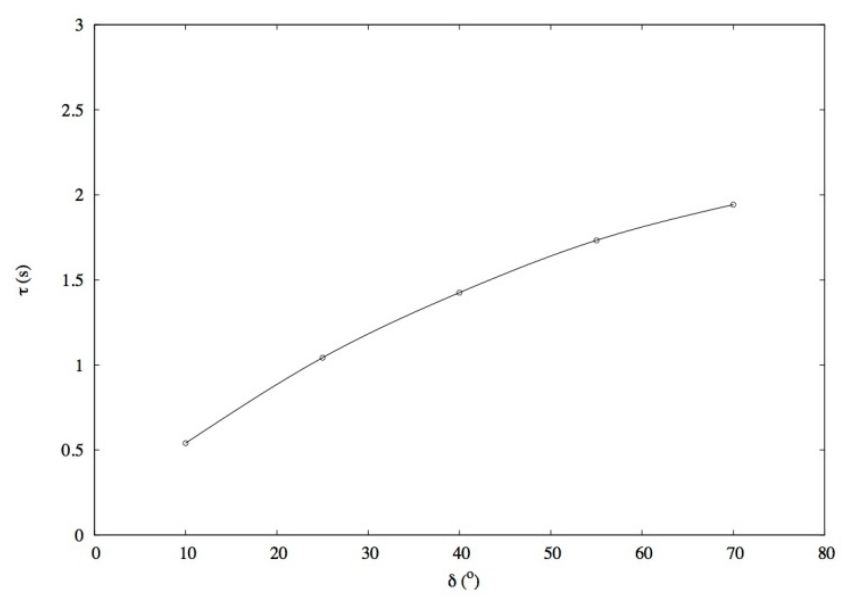

Figure 21. $\tau-\delta$ relation

Furthermore, to get an insight on how the process investigated affects the thermal behaviour of the water droplet, it is extremely interesting to examine the trend of the final droplet temperature $\mathrm{T}_{\mathrm{wf}}[\mathrm{K}]$ in dependence of the set of analysis parameters.

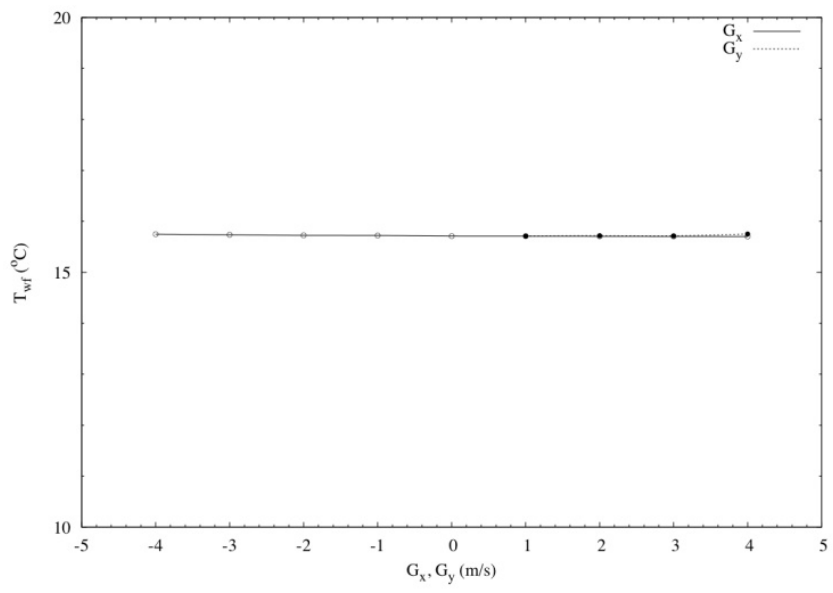

Figure 22. $\mathrm{T}_{\mathrm{wf}}$ versus $\mathrm{G}$

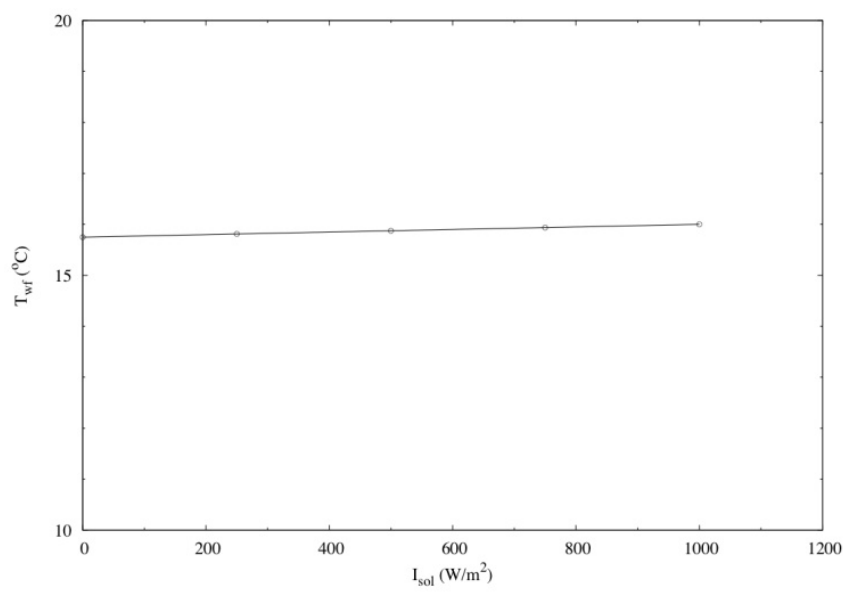

Figure 23. $T_{w f}$ versus $I_{s o l}$ 
This is not an elementary datum as it speaks not just of the phase change processes occurring but also of the dynamic one, such as the air friction effect [12]. It is not useless here to remind that, resulting $\mathrm{Bi}[-]$ always 1.t. 0.1 throughout the study, the droplet temperature was considered as uniform [11].

While Figures 22 and 23 unveil an apparently scarce

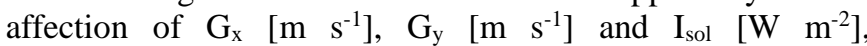
respectively, on $\mathrm{T}_{\mathrm{wf}}[\mathrm{K}]$ mainly because the corresponding dynamic and thermal inputs provided are limited with respect to the other technical and environmental variables superimposed, the other cases require deeper consideration.

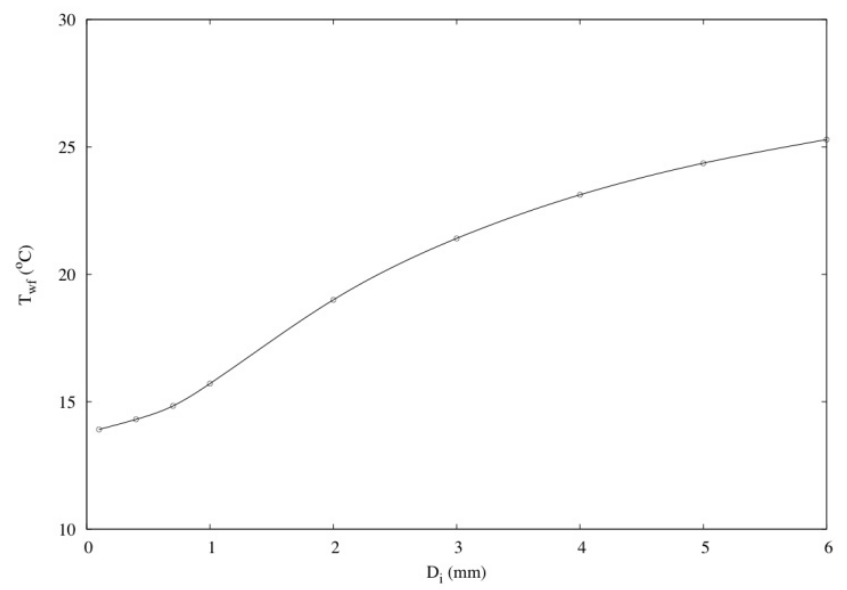

Figure 24. $T_{\mathrm{wf}}$ versus $\mathrm{D}_{\mathrm{i}}$

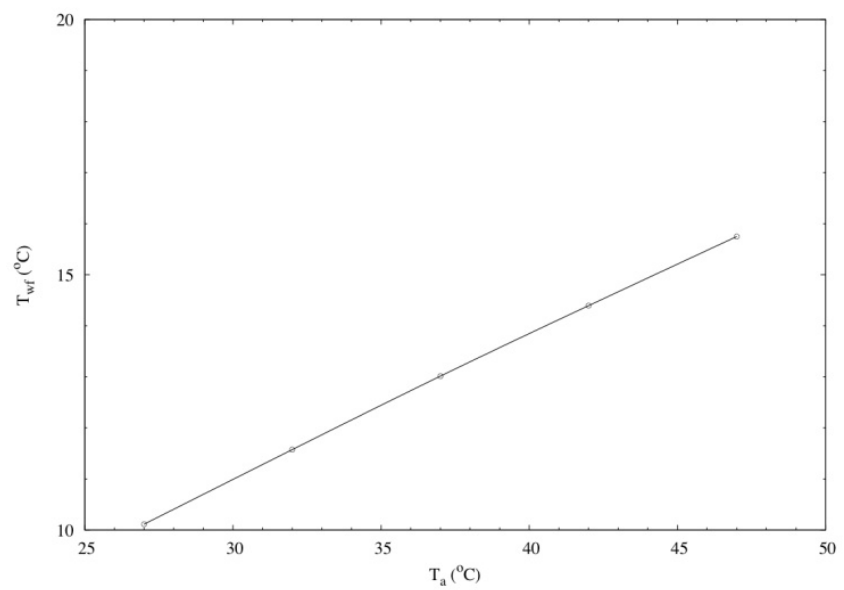

Figure 25. $\mathrm{T}_{\mathrm{wf}}$ versus $\mathrm{T}_{\mathrm{a}}$

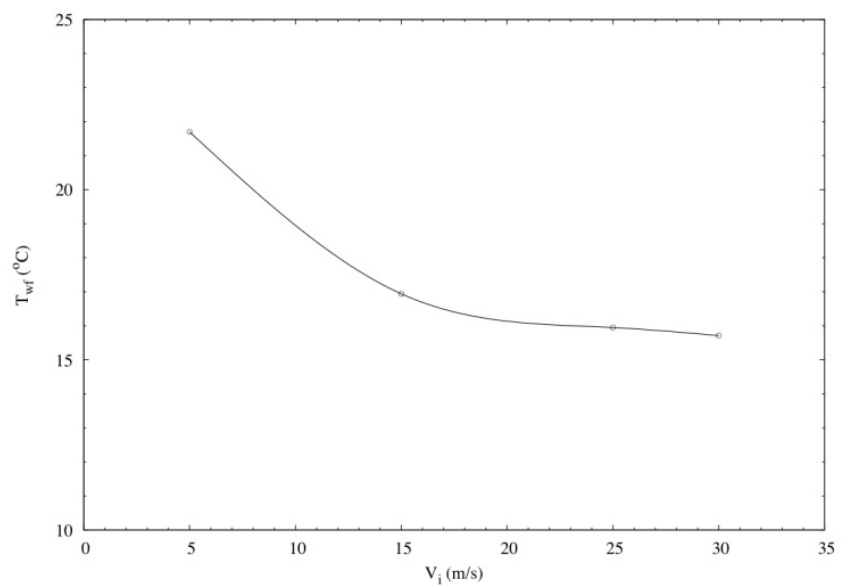

Figure 26. $\mathrm{T}_{\mathrm{wf}}$ versus $\mathrm{V}_{\mathrm{i}}$
Figure 24 examines the effect of $\mathrm{D}_{\mathrm{i}}[\mathrm{mm}]$ on $\mathrm{T}_{\mathrm{wf}}[\mathrm{K}]$ : bigger droplets chill down than smaller ones, provided they all start at $304 \mathrm{~K}$. This is to be interpreted as strictly linked to the higher evaporation occurring for smaller $\mathrm{D}_{\mathrm{i}}[\mathrm{mm}]$ values [11] and thus related to a higher latent heat flux consumption. The convective effect is instead evident in Figure 25, where higher environmental temperature results in higher final droplet temperature $\mathrm{T}_{\mathrm{wf}}[\mathrm{K}]$.

An inversely proportional trend is instead displayed in Figures 26 and 27, assessing the $V_{i}\left[\mathrm{~m} \mathrm{~s}^{-1}\right]-T_{w f}[K]$ and $D_{v-a}$ $\left[\mathrm{cm}^{2} \mathrm{~s}^{-1}\right]-\mathrm{T}_{\mathrm{wf}}[\mathrm{K}]$ relations. In the former, the enhanced convective effect, on the one hand, and the droplet time of flight, on the other, prove their effectiveness; in the latter a higher diffusion is directly linked to a higher latent heat flux.

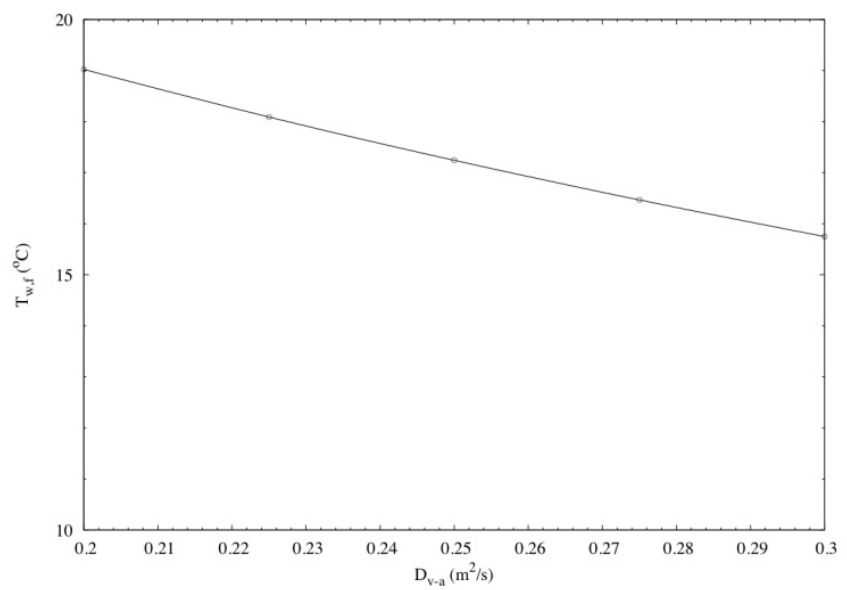

Figure 27. $T_{w f}$ versus $D_{v-a}$

The extreme reliability of the model employed is also evident when Figure 28 is spotted: an increment in $\varphi[\%]$ progressively reduces droplet evaporation, thus less latent heat flux is taken from the droplet itself and consequently $\mathrm{T}_{\mathrm{wf}}$ $[\mathrm{K}]$ soars.

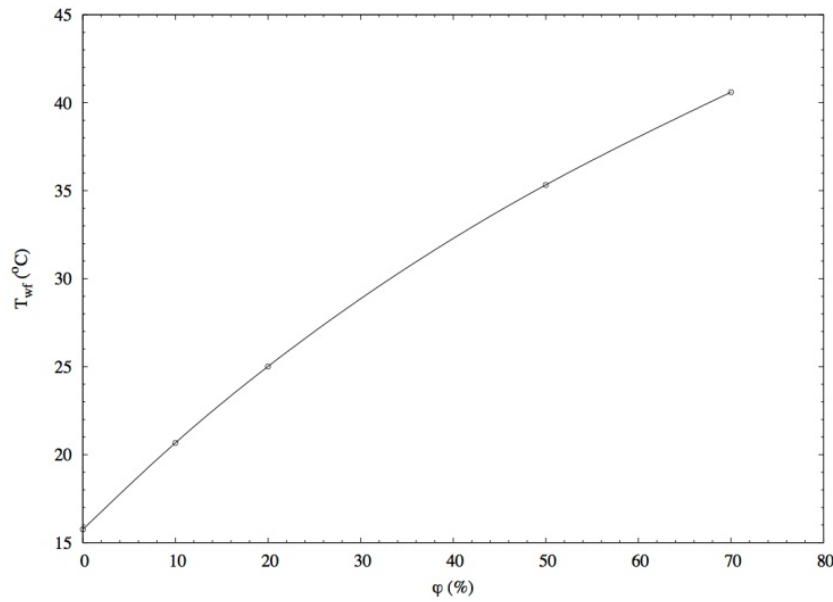

Figure 28. $\mathrm{T}_{\mathrm{wf}}$ versus $\varphi$

Not too surprisingly, instead, keeping the same general conditions, the exam of how $\mathrm{T}_{\mathrm{w}}[\mathrm{K}]$ affects $\mathrm{T}_{\mathrm{wf}}[\mathrm{K}]$ (graphed in Figure 29), highlights a direct proportionality even if with a not too strong relationship.

Moreover it is shown in Figure 30, again in association with the droplet time of flight to put in evidence their symmetrical trends, the dependence of $\mathrm{T}_{\mathrm{wf}}[\mathrm{K}]$ on the initial droplet inclination $\delta\left[^{\circ}\right]$ : when $\delta\left[^{\circ}\right]$ augments, as previously pointed out in this section, the time of flight soars, thus 
contributing to an increased evaporation and to a more intense action of the air friction, resulting in a final droplet temperature drop.

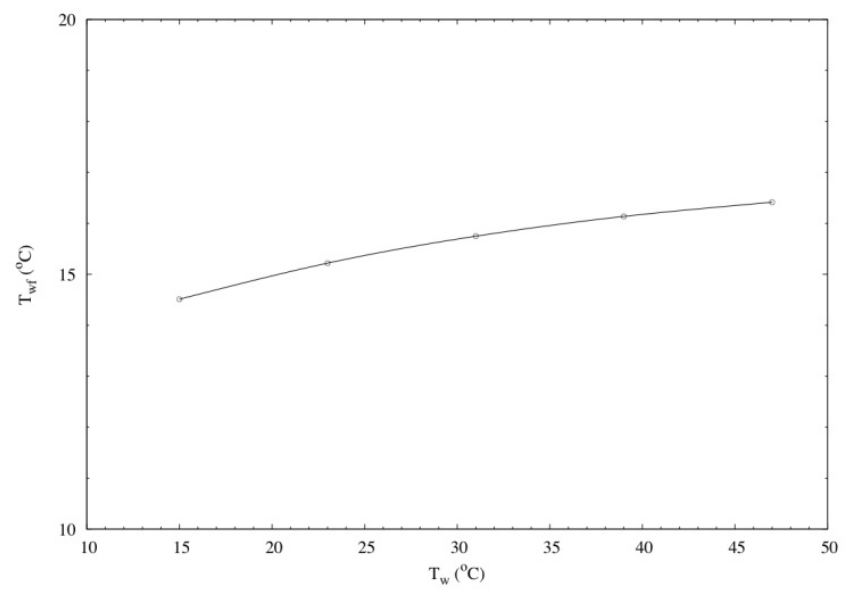

Figure 29. $T_{w f}$ versus $T_{w}$

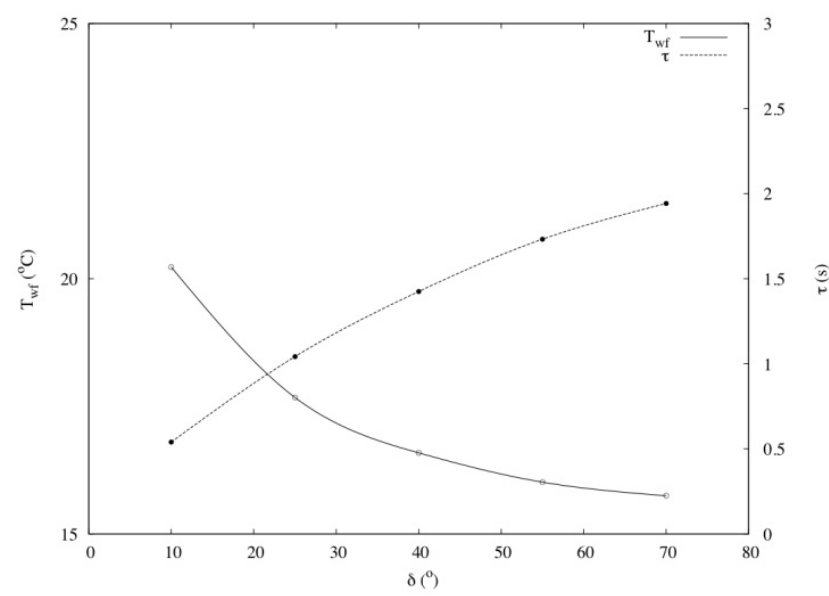

Figure 30. $\mathrm{T}_{\mathrm{wf}}$ versus $\delta$; $\tau$ versus $\delta$

\section{FINAL REMARKS}

In the research here presented we have assessed the sprinkler irrigation phenomenon of a water droplet evaporating in air during its path from the sprinkler nozzle to the ground.

All the variables (geometric, dynamic and thermalfluiddynamic) that allow for a full parametrical description of the process have been considered and explicitly treated, to arrive at a physically realistic description: initial droplet diameter, air temperature, initial droplet velocity, diffusion coefficient of water in air, wind velocity, air relative humidity, initial droplet throw inclination, initial droplet temperature and thermal radiation.

The study relied on an analytical-numerical model, recently defined and validated, which utilised a few assumptions not affecting the general applicability of its results.

The outcomes were mainly based on the representation of the effects of the analysis parameters considered (initial droplet diameter, air temperature, initial droplet velocity, diffusion coefficient of water in air, wind velocity, air relative humidity, initial droplet throw inclination, initial droplet temperature and thermal radiation) on these three variables: droplet travel distance, droplet time of flight and final droplet temperature.

The following: initial droplet diameter, initial droplet velocity and initial droplet throw inclination had a significant effect on the droplet travel distance and on the droplet time of flight. Instead: initial droplet diameter, initial droplet velocity, initial droplet throw inclination and air relative humidity had a significant effect on the final droplet temperature. Solar irradiance and wind velocity proved the least affecting variables, even if the latter has great relevance on the general dynamics of the process.

\section{REFERENCES}

[1] C.C. Tseng and R. Viskanta, "Enhancement of water droplet evaporation by radiation absorption," Fire Safety Journal, vol. 41, no. 3, pp. 236-247, 2006. DOI: 10.1016/j.firesaf.2006.01.001.

[2] G. Miliauskas and V. Sabanas, "Interaction of transfer processes during unsteady evaporation of water droplets," International Journal of Heat and Mass Transfer, vol. 49, no. 11-12, pp. 1790-1803, 2006. DOI: 10.1016/j.ijheat masstransfer.2005.11.015.

[3] G. Miliauskas, V. Sabanas, R. Bankauskas, G. Miliauskas and V. Sankauskaite, "The peculiarities of sprayed liquid's thermal state change, as droplets are heated by conduction," International Journal of Heat and Mass Transfer, vol. 51, no. 17-18, pp. 4145-4160, 2008. DOI: $10.1016 /$ j.ijheatmasstransfer.2008.01.016.

[4] G. Miliauskas and V. Garmus. "The peculiarities of hot liquid droplets heating and evaporation," International Journal of Heat and Mass Transfer, vol. 52, no. 15-16, pp. 3726-3737, 2009. DOI: 10.1016/j.ijheatmasstransfer.2009.03.001.

[5] G. Miliauskas, S. Sinkunas and G. Miliauskas, "Evaporation and condensing augmentation of water droplets in flue gas," International Journal of Heat and Mass Transfer, vol. 53, no. 5-6, pp. 1220-1230, 2010. DOI: $10.1016 /$ j.ijheatmasstransfer.2009.10.005.

[6] H. Grosshans, "Evaporation of a droplet," Project Report 2012 MVK160, Heat and Mass Transport, 2012.

[7] D. Jakubczyk, M. Zientara, K. Kolwas and M. Kolwas, "Temperature dependence of evaporation coefficient for water measured in droplets in nitrogen under atmospheric pressure," Journal of the Atmospheric Sciences, vol. 64, pp. 996-1004, 2007. DOI: 10.1175/JAS3860.1.

[8] B. Sobac and D. Brutin, "Thermal effects of the substrate on water droplet evaporation," Physical Review E., vol. 86, pp. 021602-1/021602-10, 2012. DOI: $10.1103 /$ PhysRevE.86.021602.

[9] R. S. Volkov, G. V. Kuznetsov and P. A. Strizhak, "The influence of initial sizes and velocities of water droplets on transfer characteristics at high-temperature gas flow," International Journal of Heat and Mass Transfer, vol. 79, pp. 838-845, Dec. 2014. DOI: 10.1016/j.ijheatmasstransfer.2014.09.006.

[10] R. S. Volkov, G. V. Kuznetsov and P. A. Strizhak, "Water droplet deformation in gas stream: Impact of temperature difference between liquid and gas," International Journal of Heat and Mass Transfer, vol. 85, pp. 1-11, June 2015. DOI: 10.1016/j.ijheatmasstransfer.2015.01.078. 
[11] G. Lorenzini and O. Saro, "Thermal fluid dynamic modelling of a water droplet evaporating in air," International Journal of Heat and Mass Transfer, vol. 62, pp. 323-335, July 2013. DOI: 10.1016/j.ijheatmasstransfer.2013.02.062.

[12] G. Lorenzini, "Simplified modelling of sprinkler droplet dynamics," Biosystems Engineering, vol. 87, no. $1, \quad$ pp. 1-11, 2004. DOI: 10.1016/j.biosystemseng.2003.08.015.

[13] R. B. Bird, W. E. Steward and E. N. Lightfoot, Transport Phenomena, Wiley \& Sons, 1960.

[14] D. M. Bourg, Excel Scientific and Engineering Cookbook, O’Reilly \& Associates, 2006.

\section{NOMENCLATURE}

$\begin{array}{ll}\mathrm{Bi} & \text { dimensionless Biot number } \\ \mathrm{D}_{\mathrm{i}} & \text { initial droplet diameter, } \mathrm{mm} \\ \mathrm{D}_{\mathrm{v}-\mathrm{a}} & \text { diffusion coefficient of water in air, } \mathrm{cm}^{2} \mathrm{~s}^{-1} \\ G & \text { wind velocity, } \mathrm{m} \mathrm{s}^{-1}\end{array}$

$\mathrm{T}_{\mathrm{a}}$

$\mathrm{T}_{\mathrm{wf}}$

$\mathrm{T}_{\mathrm{w}}$

$\mathbf{V}_{\mathbf{i}}$

\section{Greek symbols}

$\delta$

\section{Subscripts}

$\mathrm{x}, \mathrm{y}$
$\mathrm{z}$

$\mathrm{x}, \mathrm{y}$ $\delta$ solar irradiance, $\mathrm{W} \mathrm{m}^{-2}$

droplet travel distance, $\mathrm{m}$ droplet mass evaporated in flight, $\%$ dimensionless Prandtl number dimensionless Reynolds number dimensionless Schmidt number air temperature, $\mathrm{K}$

final droplet temperature, $\mathrm{K}$ initial droplet temperature, $\mathrm{K}$ initial droplet velocity, $\mathrm{m} \mathrm{s}^{-1}$ inlet droplet inclination, ${ }^{\circ}$ air relative humidity, $\%$ droplet time of flight, $s$

horizontal directions

vertical direction 